\title{
Impact of meaningful work on elderly people's intention to continue working after retirement: $A$ Vietnamese study
}

\author{
Thi Mai Huong Doan ${ }^{1, *}$,Huong Quynh Pham ${ }^{2}$, and Thi Mai Phuong Tran ${ }^{2}$ \\ ${ }^{1}$ University of Labour and Social Affairs, 43 Tran Duy Hung, Trung Hoa, Cau Giay, Ha Noi, Vietnam \\ ${ }^{2}$ National Economics University, 207 Giai Phong, Hai Ba Trung, Ha Noi, Vietnam
}

\begin{abstract}
The study focuses on examining the relationship between meaningful work and elderly people's intention to work after retirement. Based on the previous research, we examined the impact level of the three aspects of meaningful work, which are positive meaning, meaning making through work and greater good motivations. The analysis of a sample of 784 workers aged 40 and above showed that all three aspects considered have a positive effect on the intention to participate in the workforce after retirement. In particular, positive meaning has the strongest impact on the workers' intention. The results of the current study extend previous research on factors affecting workers' intention to continue working after retirement. The implications of these findings are discussed in the practical aspect of those involved in the development of effective human resource management policies to retain older workers.
\end{abstract}

\section{Introduction}

For a country, a rapid increase in population aging will have a negative impact on its labor market. An aging population is associated with a large number of people leaving the labor force due to retirement age, causing a shift in the labor force from young workers to older workers and shortage in the labor market. In addition, this situation creates pressure on infrastructure systems, health care and medical services and transportation as well as pension and other support systems... for the elderly (Jackson \& Peter, 2015; Keese, 2006). Therefore, in the industrially developed countries such as Austria, Finland, Japan, the United Kingdom and the United States, there is an increasing trend of employment development for post-retirement workers (Cahil et al., 2013; Dubois \& Anderson, 2012; VanKatwyk, 2012). Moreover, many studies have demonstrated that older people who continue to work after retirement are happier and healthier than those who no longer work (Kim \& Feldman, 2000; Zhan et al., 2009). Because, as noted by many researchers (Chalofsky \& Krishna, 2009; Steger et al., 2012; Lepisto \& Pratt, 2017; Wrzesniewski, 2003), work is not only about financial security but is also an important factor relating to psychological and social aspects in life that go beyond basic needs. A meaningful job helps them feel the purpose of better working and stronger commitment. Therefore, finding a

*Corresponding author: huongdoanthimai@yahoo.com 
meaningful work can create a significant motivation for older workers to continue to join the labor force after reaching the retirement age (Atchley, 1989). Meanwhile, investigating the relationship between absenteeism and job participation of the workers, Soane et al. (2013) came up with the results that proved the more meaningful the job is, the lower the absence rate at the organization becomes.

Although previous research has shown that many factors influence the worker's intention to work after retirement (eg. personal characteristics related to physical and mental health, personal finance, demographic characteristics, job-related psychological variables, family-related variables and retirement planning activities) (Fisher et al., 2016), the number of studies on the role of meaningful work in shaping the decision to continue working after retirement is still limited.

The Importance of Meaningful Work

For decades, scientists have been studying meaningful work (Bailey et al., 2019). Studies from more than 50 years ago show that up to $95 \%$ of workers in different cultures and careers are willing to continue working even when there is no financial need (Baltes et al. 2012). This suggests that the role of meaningful work shows its importance in terms of psychology and sociology (Chalofsky, 2003). According to Pratt \& Ashforth (2003), work is perceived to be meaningful when workers find it serving an important purpose. In the field of social science, meaningful work is often described as a job characteristic that employees value the most, with an emphasis on personal experience and an understanding of the meaning of life (Steger et al. 2012; Wrzesniewski et al. 1997).

A worker considers his or her job to be meaningful when the goal or the purpose of the job aligns with their own ideals or standards (Thomas \& Velthouse, 1990). Such association occurs when there is a match between job requirements and their beliefs, values and behaviors (Chalofsky, 2003). The psychological meaning of work refers to the employee's cognitive work experience, which in turn leads to positive outcomes related to the individual and the job. The research findings reveal that meaningful work involves key employee retention, effective change management, greater organizational commitment, higher organizational performance and employee engagement (Van Wingerden \& Van der Stoep, 2017). However, most of the studies have been conducted on employees in general, and are quite lacking in the research applicable to elderly workers while, in practice, there are differences between the job perspectives of different ages. Therefore, this can be considered a gap that we can deploy research.

\section{Retirement}

Not only the developed countries face population aging, but Vietnam, one of the developing countries, also deals with this issue. According to the Vietnamese population forecast from 2014 to 2049 , the percentage of the population aged 65 and above will increase from $7.1 \%$ in 2014 to $18.1 \%$ in 2049 and the "golden population structure" period of our country will end in 2040 as at this time the proportion of the population aged 65 years and above will begin to exceed 15\% (General Statistics Office \& United Nations Population Fund, 2016). Therefore, from now on, the State needs to be well-prepared in proposing practical, centralized and effective intervention policies and programs. One of the proposed solutions to this problem is to attract the elderly workforce to continue working after retirement, especially the elderly in urban areas (World Bank, 2016). In practice, while previously, $86 \%$ of current retirees in Vietnam said they retired before reaching the age of 60 , only $32 \%$ of the Vietnamese now agree with the view that "they should retire at a determined age and should not return to work". In other words, current workers tend to expect their retirement at a later age than current retirees (Jackson and Peter, 2015). If the experience and skills of these retirees (pensioners) can be effectively exploited, they will make a positive economic contribution. Healthy elderly workers with 
extensive work experience can support the young workforce to achieve higher productivity (Tiep, 2012).

In the traditional original sense, retirement is a departure from public space, "social death". The individual ceases to work and limits his studies to the private sphere: household chores, leisure, communication with family and friends. K. Gini believed that aging is a source the occurrence of significant conflicts, since the elderly are more or less professionally passive and therefore, from an economic point of view, they become a heavy burden for the people from day to day (Radushinsky et al., 2018).

However, such a theoretical idea of pensioners in practice often turns out to be false. Three types of retirement lifestyle can be distinguished, depending on the degree of involvement of pensioners in activities in the public space. The first type: retirees continue to be present in the public space as they did before reaching retirement age. The second type (opposite): pensioners are completely eliminated from public space, and their activities and relationships are limited to the private sphere. The third type (intermediate): pensioners combine classes in public and private spheres. Thus, retirees can continue to be present in the public space. Pensioners do not necessarily stop working.

Social inclusion / exclusion has a spatial aspect: a substantial part of personal relationships and activities (that is, social connections) refers to a specific territory. The risk of social exclusion of pensioners is often associated not so much with retirement as with aging and a significant deterioration in health status. Features of the urban environment (safety, accessibility and comfort) affect the social inclusion of pensioners, contributing to its expansion or contraction. To ensure the social inclusion of pensioners, certain conditions of the urban space in which they live are necessary, adapted to the specifics of their physical capabilities, including: accessibility and convenience of urban space, the reliability of public transport, accessibility of public places (the presence of escalators and elevators, the ability to move in a wheelchair). The studies had showed that not only the urban environment of the metropolis creates conditions for pensioners, but the social inclusion of pensioners contributes to the well-being of their social environment and the metropolis as a whole (Radushinsky et al., 2019).

In European countries, for example in France, despite the mandatory retirement of 65 years, some professions have the opportunity to maintain private practice, to engage in professional counseling. Pension allows some to change jobs and even find themselves in a new profession, despite the fact that a new occupation does not guarantee a stable income. That is, reaching retirement age does not necessarily mean leaving the labor market and the life of the professional community.

Pensioners can remain active in the economic sphere of society. Moreover, they are characterized by production behavior not only in relation to the production of market values. Pensioners' domestic work and the assistance they provide to children in housekeeping are also included in the gross domestic product. In many countries, some respondents also provide financial assistance to their children and grandchildren. European pensioners, in contrast to many of Vietnamese, are in a fairly prosperous economic situation. This allows them, on the one hand, to help children and grandchildren, and on the other - to diversify their leisure time, travel, etc. Lack of income often serves as a motive for the continuation of labor activity by Vietnamese pensioners. At the same time, often not being able to help their children and grandchildren with finances, Vietnamese pensioners are more likely than European to engage in grandchildren and help their children with household chores. Moreover, in general, the health status of European pensioners is also better. Therefore, thirdly, European pensioners are more mobile: they travel more, walk, etc.

In Europe, a significant portion of pensioners is involved in the activities of a particular subject of civil society. Public and professional organizations in which pensioners take part 
are often territorial in nature. They may relate to a particular house, block, or county. These organizations can do charity work, for example, teaching the French or other European language to immigrants, organizing food for the poor, helping children falling behind in school, etc. These organizations use both the general knowledge of senior citizens and their professional knowledge and skills. Moreover, often retired people from educated layers of the population participate, as a rule, in at least two organizations of this kind. At the local level, European retirees have the necessary institutional capacity to bring their opinions to the attention of the authorities and participate in various local decisions, contributing directly to the development of the metropolis. About $80 \%$ of European retirees named meaningful work as the best alternative for solicitude at the retirement ages (Gorokhova et al., 2019).

\subsection{Aim and hypotheses}

Thus, due to the importance of meaningful work, and the urgency to attract elderly workers in Vietnam to continue to engage in the labor market, we investigate the impact of meaningful work on the intention to continue working after retirement of middle-aged workers aged 40 and above who are currently working in agencies and organizations. The aim is to understand the role of meaningful work in the behavioral intentions of elderly workers. Specifically, based on previous research, we distinguish three types of meaningful work which are positive meaning, meaning making through work and greater good motivations to assess the impact level. Therefore, the current research provides a deeper understanding of the meaningful work that may affect the actual intention to continue working after the worker retires.

Our proposed hypotheses are:

Hypothesis H1 : Positive meaning has a positive impact on the employee's intention to continue working after retirement

Hypothesis H2 : Meaning making through work has a positive impact on the employee's intention to continue working after retirement

Hypothesis H3 : Greater good motivations have a positive impact on employees' intention to continue working after retirement

\section{Applied methodology}

\subsection{Participants and Procedure}

With the support of organizations and businesses, in this study, surveys were sent to employees mainly through the direct approach and a small number were delivered via email. The total number of surveys handed out is 1150 while the total number received is 928 (the response rate reached $80.7 \%$ ). However, the number of valid surveys used for analysis is only 682 .

The sample consisted of employees working for organizations aging from 40 to 59, with an average age of $46.79(\mathrm{SD}=4,797)$. Among these, $55.1 \%$ are female and $44.9 \%$ are male. The percentage of employees with a university or higher education degree is $43.4 \%$, but the proportion of people with an income of 10 million VND or higher is only $25.7 \%$. The percentage of employees working in state-owned organizations is $62.1 \%$. Regarding the working seniority, employees with working experience of 20 years or more accounts for $40.6 \%$, those from 10 to less than 20 years make $42.0 \%$ and the rest under 10 years is $17.4 \%$ (Table 1 ). 
Table 1. Participant demographics $(n=682)$.

\begin{tabular}{|l|l|c|c|}
\hline \multicolumn{1}{|c|}{ Item } & \multicolumn{1}{|c|}{ Category } & Frequency & Percentage \\
\hline Gender & Male & 306 & 44.9 \\
\hline & Female & 376 & 55.1 \\
\hline Age & $40-45$ years & 323 & 47.3 \\
\hline & $46-50$ years & 228 & 33.4 \\
\hline & $51-55$ years & 114 & 16.6 \\
\hline & $56-60$ years & 19 & 2.7 \\
\hline Qualifications & Grade 12 & 199 & 29.2 \\
\hline & Diploma & 187 & 27.4 \\
\hline & Degree & 277 & 40.6 \\
\hline & Master's or Doctoral Degree & 19 & 2.8 \\
\hline Job Tenure & Up to 4 years & 44 & 6.5 \\
\hline & 5 to 9 years & 75 & 11.0 \\
\hline & 10 to 14 years & 115 & 16.9 \\
\hline & 15 to 19 years & 172 & 25.2 \\
\hline & 20+ years & 277 & 40.6 \\
\hline Organization & Public sector & 436 & 63.9 \\
\hline & Private sector & 246 & 36.1 \\
\hline \multirow{2}{*}{$\begin{array}{l}\text { Current Salary } \\
\text { Level }\end{array}$} & Below 5 million VND & 89 & 13.0 \\
\cline { 2 - 4 } & 5 million - below 10 million VND & 418 & 61.3 \\
\hline & 10 million VND and above & 175 & 25.7 \\
\hline
\end{tabular}

\subsection{Measures}

Two key concepts used in this study are: meaningful work and the intention to continue working of an employee after retirement. Therefore, the measurement scale for these two main concepts is adopted from previous studies and adjusted to suit the Vietnamese cultural context. The scales use the 5-point Likert scale, in which 1 refers to strongly disagree and 5 is strongly agree.

\subsection{Meaningful Work}

In the current study, we have adapted from the Work and Meaning Inventory (WAMI) scale of Steger et al. (2012). This scale includes 10 observed variables, measuring three aspects, namely:

- Aspect 1: The positive meaning consists of four observed variables (e.g. "I have found a meaningful career").

- Aspect 2: Meaning making through work consists of three observed variables (e.g. "My work helps me better understand myself").

- Aspect 3: Greater good motivations include three observed variables (e.g. "The work I do serves a greater purpose").

\subsection{Intention to continue working after retirement age}

The scale measuring the workers' intention to continue working after retirement includes an observed variable adopted and adjusted from the scale by Zaniboni and Fraccaroli (2010). In particular, the survey participants will have to explain their perspectives for saying: "After retirement, I would be willing to continue to work at an organization if I have the opportunity to be recruited (This organization is not necessarily the organization that I am currently working at)" 


\section{Results}

\subsection{Preliminary Analysis}

The Cronbach alpha method is used to evaluate the reliability of the EFA factor scale and analysis method (with PAF extraction and Promax rotation - The WAMI-10 items were subjected to a principal axis factor analysis with Promax rotation) and to assess the correlation and distinguishing values of the scale. The analysis results show that all scales meet the requirements of reliability and correlation values (Hair et al., 2010).

Table 2. Means, Standard deviations, Reliability Coefficients, and Correlations $(N=682)$.

\begin{tabular}{|l|c|c|c|c|c|c|}
\hline \multicolumn{1}{|c|}{ Variable $^{\mathbf{a}}$} & \multirow{2}{*}{$\mathbf{M}^{\mathbf{a}}$} & \multirow{2}{*}{ SD } & \multirow{2}{*}{$\mathbf{A}$} & \multicolumn{3}{c|}{ Correlations } \\
\cline { 5 - 7 } & & & & $\mathbf{1}$ & $\mathbf{2}$ & $\mathbf{3}$ \\
\hline 1. Positive meaning & 3.87 & 0.912 & 0.864 & - & & \\
\hline 2. Meaning making through work & 3.05 & 1.108 & 0.767 & .001 & - & \\
\hline 3. Greater good motivations & 3.13 & 1.107 & 0.773 & .002 & $-.117^{*}$ & - \\
\hline 4. Intention to continue working & 3.80 & 1.186 & & $.584^{* *}$ & $.105^{* *}$ & $.126^{* *}$ \\
\hline
\end{tabular}

Notes: ${ }^{a}$ Scales used for variables: \#1 - \#4:1 = strongly disagree, to $5=$ strongly agree, $\alpha$ : Cronbach's alpha coefficients of the scales. ${ }^{*} \mathrm{p}<.05 ;{ }^{* *} \mathrm{p}<.01 ; * * \mathrm{p}<.001$

The EFA results show that there are 03 components extracted with a total variance extracted of $59.65 \%$ at the eigen-value of 1,855$)$. Moreover, the measured variables are all highly weighted $(\geq 0.5)$ on the concept they measure and low on the concept they do not measure. In addition, according to Table 02, Cronbach alpha of the scales shows high reliability level (from 0.76 to 0.86 ).

\subsection{Regressions}

The multivariate regression analysis method is used with the aid of SPSS 22 software to test models and research hypotheses. The first model only considers the effect of the control variables on the dependent variable. Control variables are discontinuous variables so dummy variables are used in the analysis. The second model consists of all the control variables of the first model and the independent variables which are the aspects of meaningful work including positive meaning, meaning making through work and greater good motivations. The test results of the two models are presented in Table 3.

Table 3. Results of multivariate regressions analysis on employees' intention to continue working after retirement age.

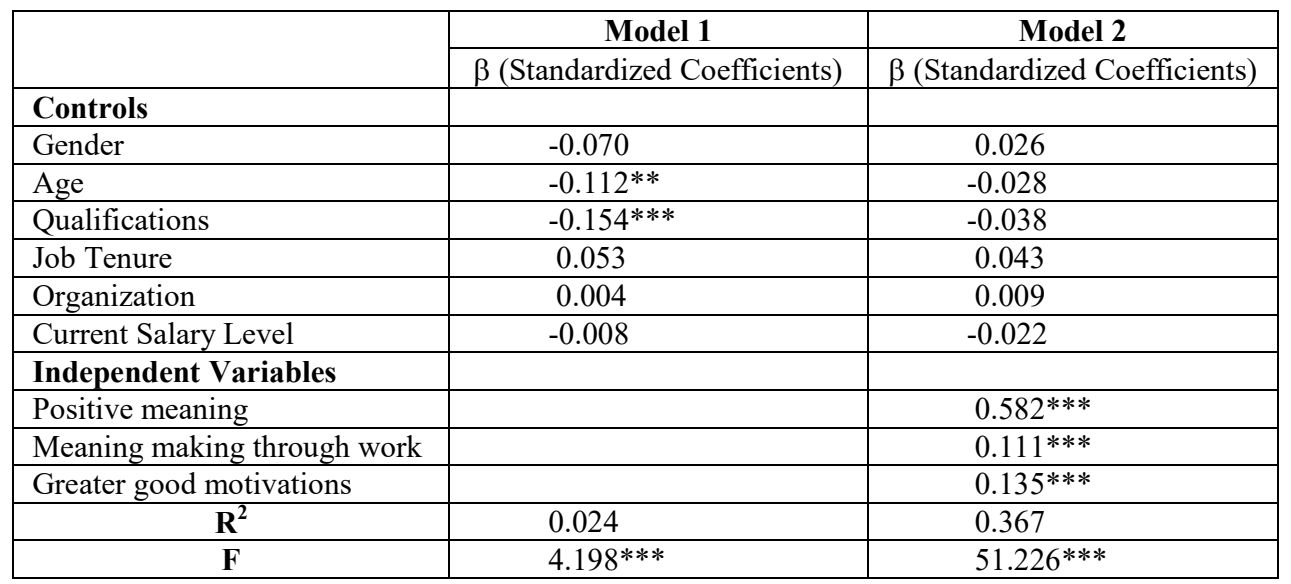


Where: $* \mathrm{p}<.05 ; * * \mathrm{p}<.01 ; * * * \mathrm{p}<.001$

According to Table 3, the first model (the control model) demonstrates statistical significance $(\mathrm{F}=4.198, \mathrm{p}<0.001)$. The analysis results reveal that age and education are related to the intention to continue working. When 3 independent variables are included, the second model is still statistically significant $(F=51,226, p<0.001)$. The analysis results of the second model show (in Table 03) that the correlation coefficient $\mathrm{R}$ has been proved to be a non-decreasing function by the number of independent variables included in the model. Especially, the adjusted R2 coefficient of 0.367 indicates good compatibility between the model and the observed variable, with $36.7 \%$ of the variation of the dependent variable of "Intention to continue working" is explained by the three factors of meaningful work. Accordingly, "positive meaning" has a positive effect on the "intention to continue working" $(\beta=0.582, p<0.001)$. Similarly, "meaning making through work" and "greater good motivations" also have positive effects on the "intention to continue working" ( $\beta=$ $0.111, \mathrm{p}<0.001$ and $\beta=0.135, \mathrm{p}<0.001$ ). Thus, the hypotheses H1, H2 and H3 are accepted. The research results will be discussed in the next section.

\section{Discussion}

The results of the current study extend previous research on the intention to work after retirement in both theory and practice. Theoretically, the current research is one of the few studies examining how meaningful work is related to the intention to engage in employment after retirement. Our results are consistent with the role of meaningful work as a guiding principle for orienting the career behavior intention of the older workers. In particular, we have expanded the study related to the intrinsic role of work by studying different aspects of meaningful work. Our results emphasize that meaningful work has the most positive psychological impact on the intention to continue working after retirement.

Practically, the defined relationship between meaningful work and the intention to work post-retirement motivates positive individual and organizational outcomes, such as postretirement career path planning and the organizational recruitment strategy. Firstly, understanding meaningful work can assist in appropriate career decision making and enhance retirement adjustment. Individuals can discuss their personal meaning of work with close friends, family and relevant colleagues. Moreover, career consultants should figure the meaningful work as they discuss the decisions on whether to continue working after retirement. Secondly, organizational recruitment strategies can originate from the current findings. Those who strongly uphold the meaningful work (especially in terms of social and personal work meaning) can be identified as the accessible human capital. For internal recruitment, organizations may use methods to assess the individual meaningful work of their employees. The relevant target group analysis assists organizations in the planning and effective application of human resource strategies at a later time. For example, strategies to retain employees may include communicating the relevant benefits of postretirement employment or training supervisors to be aware of the various aspects of meaningful work and the connection to the workplace. For external recruitment, organizations can use the knowledge relevant to meaningful work to create specific marketing actions of the target group outside their company (e.g. advertising to address the personal and social meaning of work). In summary, defining meaningful work will help managers to make effective and practical HRM policies that are applicable to the elderly employees. 


\section{Conclusion}

In summary, this study has enhanced our understanding of the relationship between meaningful work and the workers' intention to continue working after retirement. It proves that in the present volatile, uncertain, complex and ambiguous world, meaningful work acts as a motivation for the elderly to continue to engage in the labor market. Therefore, we hope that this study will motivate other researchers to explore more about the psychological mechanisms that bring about meaningful work that affects the behaviors of elderly people after retirement. It is important that future studies need to assess the motivations and values that drive beliefs about meaningful work, thereby determining a more direct motivation for post-retirement employment decisions.

\section{References}

1. R.C. Atchley, The gerontologist 29(2), 183-190 (1989)

2. C. Bailey, R. Yeoman, A. Madden, M. Thompson, G. Kerridge, Human Resource Development Review 18(1), 83-113 (2019)

3. B.B. Baltes, C.W. Rudolph, A.C. Bal, A review of aging theories and modern work perspectives. The Oxford handbook of work and aging (2012)

4. T. Gorokhova, L. Pushkareva, M. Sredin, M. Pushkarev, E3S Web Conf. (ITESE-2019) 135, 04069 (2019) DOI: https://doi.org/10.1051/e3sconf/201913504069

5. K.E. Cahill, M.D. Giandrea, J.F. Quinn, Bridge employment. The Oxford Handbook of Retirement (Oxford University Press, New York, 2013)

6. N. Chalofsky, Human Resource Development International 6(1), 69-83 (2003)

7. N. Chalofsky, V. Krishna, Advances in Developing Human Resources 11(2), 189-203 (2009)

8. H.F. Dubois, R. Anderson, Income from work after retirement in the EU (Publications Office of the European Union, 2012)

9. G.G. Fisher, D.S. Chaffee, A. Sonnega, Aging and Retirement 2(2), 230-261 (2016)

10. General Statistics Office \& United Nations Population Fund. Vietnam Population Projection 2014-2049 (Vietnam News Agency Publishing House, Hanoi, 2016)

11. J.F. Hair, W.C. Black, B.J. Babin, R.E. Anderson, Multivariate data analysis $7^{\text {th }}$ Prentice hall (Upper Saddle River, New Jersey, 2010)

12. R. Jackson, T. Peter, From challenge to opportunity: Wave 2 of the East Asia retirement survey (Global Aging Institute, 2015)

13. M. Keese, Live longer, work longer (Univerza v Ljubljani, Ekonomska fakulteta, 2006)

14. S. Kim, D.C. Feldman, Academy of management Journal 43(6), 1195-1210 (2000)

15. D.A. Lepisto, M.G. Pratt, Organizational Psychology Review 7, 99-121 (2017)

16. M.G. Pratt, B.E. Ashforth, Foundations of a new discipline 309, 327 (2003)

17. D. Radushinsky, E. Markovskaya, et al., MATEC Web of Conferences, SPbWOSCE2017 Business Technologies for Sustainable Urban Development, 01047 (2018) DOI: $10.1051 /$ matecconf $/ 201817001047$

18. D. Radushinsky, T.M.H. Doan, V.L. Nguyen, M. Gubankova, et al., E3S Web Conf. (ITESE-2019) 135, 04054 (2019) DOI: 10.1051/e3sconf/201913504054

19. E. Soane, A. Shantz, K. Alfes, C. Truss, C. Rees, M. Gatenby, Human resource management 52(3), 441-456 (2013). 
20. M.F. Steger, B.J. Dik, R.D. Duffy, Journal of career Assessment 20(3), 322-337 (2012)

21. Thi Mai Huong Doan, Effective solutions for elderly labour usage, Ministerial level topic (2018)

22. K.W. Thomas, B.E. Velthouse, Academy of Management Review 15, 666-681 (1990)

23. P.T. Van Katwyk, The changing workforce demographics in Asia Pacific. The Oxford handbook of work and aging (2012)

24. J. Van Wingerden, J.J. Van der Stoep, International Journal of Human Resource Studies 7(4), 23-37 (2017)

25. World Bank Live Long and Prosper: Aging in East Asia and Pacific, International Bank for Reconstruction and Development (The World Bank, Washington, 2016)

26. A. Wrzesniewski, C. McCauley, P. Rozin, B. Schwartz, Journal of Research in Personality 31, 21-33 (1997)

27. A. Wrzesniewski, Finding positive meaning in work. Positive organizational scholarship: Foundations of a new discipline (2003)

28. S. Zaniboni, G. Sarchielli, F. Fraccaroli, International Journal of Manpower 31(3), 271285 (2010)

29. Y. Zhan, M. Wang, S. Liu, K.S. Shultz, Journal of occupational health psychology 14(4), 374 (2009) 